\title{
Da proteção jurídica das pessoas com deficiência no sistema jurídico brasileiro*
}

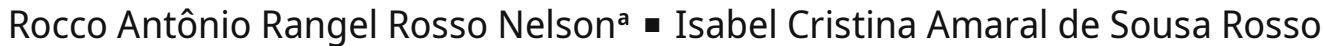 \\ Nelson ${ }^{\mathbf{b}}$ - Eliton de Souza Costac
}

\begin{abstract}
Resumo: Na quadra histórica em que vive o Brasil, no qual quase 25\% da população é detentora de alguma deficiência, chegando em alguns Estados da federação a ultrapassar a marca dos 27\% de pessoas com deficiência, vem-se por questionar que tutelas jurídicas o direito vem proporcionando a essa parcela da população brasileira. Nesse estudo será ponderada a recentíssima Lei nº 13.146/15 que lavra o Estatuto da pessoa com deficiência, a qual oferta uma nova modelagem jurídica ao tratamento destinado a inclusão de pessoa com deficiência, inovando em certos momentos e consolidando outras matérias. A presente pesquisa, fazendo uso de uma metodologia de análise qualitativa, usando-se os métodos de abordagem hipotético-dedutivos de caráter descritivo e analítico, tem por objetivo estudar o plexo de direitos e garantias relacionado com as pessoas com deficiência, desenhando o microssistema jurídico especial galgado pela normatividade extraída da constituição e dos diversos ramos do direito.
\end{abstract}

Palavras-chave: Dignidade da pessoa humana; Direitos; Pessoas com deficiência

Data de recebimento: 14 de abril de 2019 Data de avaliação: 23 de junho de 2019

Data de aprovação: 27 de junho de 2019

* Artículo de investigación elaborado de estudio desarrollado en la línea de investigación "Democracia, Ciudadanía y Derechos Fundamentales", inscrito en el Grupo de Estudio e Investigación en Extensión y Responsabilidad Social, del Instituto Federal de Rio Grande do Norte - IFRN, Brasil.

a Mestre em Direito Constitucional pela Universidade Federal do Rio Grande do Norte - UFRN. Especialista em Ministério Público, Direito e Cidadania pela Escola Superior do Ministério Público do Rio Grande do Norte.

Correo electrónico: rocconelson@hotmail.com / rocco.nelson@ifrn.edu.br ORCID: https://orcid.org/0000-0002-4169-1827

b Doutora em Educação pela Universidade Federal do Rio Grande do Norte - UFRn. Bacharela e licenciada em enfermagem pela Universidade Estadual da Paraíba - UEPB.

Correo electrónico: isacristas@yahoo.com.br ORCID: https://orcid.org/0000-0003-4840-6950

c Cientista Social pela Universidade Federal do Rio Grande do Norte - UFRN. Especialista em Antropologia pela Universidade Federal do Rio Grande do Norte - UFRN.

Correo electrónico: eliton.souza@ifrn.edu.br ORCID: https://orcid.org/0000-0002-5609-9586 
Cómo citar: Rangel Rosso Nelson R.C., Amaral de Sousa Rosso Nelson I. C., de Souza Costa E. (2019). Da proteção jurídica das pessoas com deficiência no sistema jurídico brasileiro. Revista Prolegómenos, 22(44), pp. 97-116. DOI: https://doi.org/10.18359/prole.4055

\title{
On the Legal Protection of Persons with Disabilities in the Brazilian Legal System
}

\begin{abstract}
In this historical period Brazil is going through, in which almost $25 \%$ of the population has some disability — while in some states this figure rises to more than $27 \%$-, it has been questioned what legal protection this sector of the Brazilian population receives by right. This study considers the very recent Law No. 13.146/15, which modifies the persons with disabilities act and offers a new legal model for their treatment, innovating in some cases and consolidating other elements.

Using a qualitative analysis and a hypothetical-deductive approach of a descriptive and analytical nature, this research aims at reviewing the set of rights and guarantees of persons with disabilities, tracing the special legal microsystem conquered by the regulations drawn from the constitution and various branches of law.
\end{abstract}

Keywords: Human dignity; rights; persons with disabilities

\section{Sobre la protección jurídica de las personas con discapacidad en el sistema jurídico brasileño}

Resumen: En este periodo histórico que está viviendo Brasil, en el que casi el 25\% de la población tiene alguna discapacidad — mientras que en algunos estados esta cifra se eleva a más del 27\% — se ha cuestionado qué protección jurídica recibe por derecho este sector de la población brasileña. En este estudio se considerará la muy reciente Ley N. 13.146/15, que modifica el Estatuto de las personas con discapacidad y ofrece un nuevo modelo legal para el trato de personas con discapacidad, innovando en algunos casos y consolidando otros elementos.

Esta investigación -a través de una metodología de análisis cualitativo y de métodos de abordaje hipotético-deductivos de carácter descriptivo y analítico- tiene como objetivo estudiar el conjunto de derechos y garantías relacionado con las personas con discapacidad, trazando el microsistema jurídico especial conquistado por la normatividad extraída de la constitución y de las diversas ramas del derecho.

Palabras clave: Dignidad del ser humano; Derechos; Personas con discapacidad 


\section{Introdução}

A figura da deficiência como algo diferente do tido como "normal" sempre foi tratado com teor pejorativo, as vezes relacionado com forças malignas, cuja "imperfeição" acarretava a morte do recém-nascido, na antiguidade.

Por muito tempo a deficiência fora vista, exclusivamente, pela perspectiva médica, de forma isolada, associada a alguma patologia. Em suma, ser deficiente era ser uma pessoa doente.

A percepção médica da deficiência falha por não visualizar o incidente de forma contextualizada, vendo a deficiência em si mesma, como problema de um indivíduo que foge de um padrão homogeneizado do ser perfeito. ${ }^{1}$

Entretanto, quando do olhar, a partir do modelo social, a deficiência não está no indivíduo, mas sim nas barreiras existentes da dinâmica de interação entre corpo social e indivíduo. O deficiente, não é deficiente, mas sim diferente, como todos, assim o são. Nessa modelação tem-se o reconhecimento da diversidade que compõe a sociedade. ${ }^{2}$

1 "O modelo médico de deficiência atribui os problemas encontrados pela pessoa com deficiência à sua própria condição, ou seja, condição de possível incapacidade de preencher as condições necessárias para a participação social.” (...).

A deficiência assume o significado de doença, e toda e qualquer intervenção educacional busca promover intervenções que curem o problema da pessoa com deficiência. Portanto, em educação se assume uma constante preocupação com o diagnóstico da deficiência, buscando classificar o anormal para depois intervir, assim, o professor com seu olhar diagnóstico deve ser capaz de avaliar e realizar o tratamento no sentido da cura. (...)". (Carvalho \& Naujorks, 2006, p. 02)

2 "Nessa perspectiva, a problemática da deficiência não está na pessoa que apresenta tal condição, mas na forma como a pessoa deficiente é concebida na sociedade. Assim, o modelo social reconhece a singularidade da pessoa e não a sua deficiência, singularidade essa que a torna diferente de todas as outras pessoas, pois se parte do entendimento de que cada pessoa é única. Nesse sentido, a sociedade deve adaptar-se para responder as necessidades de todos os seus membros, pois o contexto social assume um papel decisivo como favorecedor ou
Nesses termos Claudia Werneck (2005):

O Social Disability Movement provou que as dificuldades - ou a maior parte das dificuldades - enfrentadas por pessoas com deficiência são resultado da forma pela qual a sociedade lida com as limitações e as sequelas físicas, intelectuais, sensoriais e múltiplas de cada indivíduo.

De acordo com o modelo social, a deficiência é a soma de duas condições inseparáveis: as sequelas existentes no corpo e as barreiras físicas, econômicas e sociais impostas pelo ambiente ao indivíduo que tem essas sequelas. Sob esta ótica, é possível entender a deficiência como uma construção coletiva entre indivíduos (com e sem deficiência) e a sociedade. Ao mesmo tempo em que as limitações de uma pessoa são uma realidade concreta, já há um entendimento claro de que a deficiência é apenas uma das características daquele indivíduo, uma parte, que não deve refletir o seu todo. (p. 27)3

No modelo de concepção social da deficiência, visão mais moderna e de caráter humanescente, encontra-se no seio da definição de pessoa com deficiência dada pela Convenção Internacional sobre os Direitos das Pessoas com Deficiência, assinado em Nova York, em 2007, ratificado do Brasil, por meio do decreto $n^{\circ}$ 6.949/09:

Pessoas com deficiência são aquelas que têm impedimentos de longo prazo de natureza física, mental, intelectual ou sensorial, os quais, em interação com diversas barreiras, podem obstruir sua participação plena e efetiva na sociedade em igualdades de condições com as demais pessoas.

impeditivo do processo de desenvolvimento das pessoas que nele se encontram inseridas”. (Carvalho \& Naujorks, 2006, p. 02).

3 "O modelo social tem permitido à pessoa com deficiência retomar o controle de sua própria vida e ainda ter o poder de tomar decisões nos meios sociais, participando ativa e politicamente de sua comunidade. Esta abordagem leva a compreender que o problema não está na pessoa ou na sua deficiência, mas que a deficiência assume uma dimensão social que leva à exclusão. Este modelo argumenta do ponto de vista sociopolítico, que a deficiência resulta da falha da sociedade, (...)”. (Augustin, 2012). 
É fulcral a necessidade da mudança do paradigma social de forma a perceber a pessoa com deficiência como pessoa, como mais um integrante da sociedade, derrubando os muros do preconceito, pois estar-se-á a marginalizar quase $1 / 4$ da população brasileira, como constato no sensu de 2010.

Tabela 01. Quantitativo proporcional de pessoas com deficiência por Estado - Brasil, $2010^{4}$

\begin{tabular}{|c|c|c|}
\hline Unidade da Federação & $\begin{array}{l}\text { População com } \\
\text { deficiência }\end{array}$ & $\% *$ \\
\hline Rio Grande do Norte & 882.681 hab. & 27,86 \\
\hline Paraíba & 1.045.631 hab. & 27,76 \\
\hline Ceará & 2.340.150 hab. & 27,69 \\
\hline Piauí & 860.430 hab. & 27,59 \\
\hline Pernambuco & 2.426.106 hab. & 27,58 \\
\hline Alagoas & 859.515 hab. & 27,54 \\
\hline Bahia & 3.558.895 hab. & 25,39 \\
\hline Maranhão & 1.641.404 hab. & 24,97 \\
\hline Rio de Janeiro & 3.900.870 hab. & 24,4 \\
\hline Rio Grande do Sul & 2.549.691 hab. & 23,84 \\
\hline Amapá & 158.749 hab. & 23,71 \\
\hline Pará & 1.791.299 hab. & 23,63 \\
\hline Espírito Santo & 824.095 hab. & 23,45 \\
\hline Goiás & 1.393.540 hab. & 23,21 \\
\hline Amazonas & 791.162 hab. & 22,71 \\
\hline São Paulo & 9.349.553 hab. & 22,66 \\
\hline Minas Gerais & 4.432456 hab. & 22,62 \\
\hline Acre & 165.823 hab. & 22,61 \\
\hline Distrito Federal & 574.275 hab. & 22,34 \\
\hline Tocantins & 307.350 hab. & 22,22 \\
\hline Rondônia & 345.411 hab. & 22,11 \\
\hline Mato Grosso & 669.010 hab. & 22,04 \\
\hline Paraná & 2.283.022 hab. & 21,86 \\
\hline
\end{tabular}

4 Cf. Brasil. Cartilha do Censo 2010 - pessoas com deficiência. 2012. Disponível em: http://www.unievangelica.edu.br/novo/img/nucleo/cartilha-censo-2010-pessoas-com-deficienciareduzido.pdf

\begin{tabular}{lll}
\hline Mato Grosso do Sul & 526.672 hab. & 21,51 \\
\hline Santa Catarina & 1.331 .445 hab. & 21,31 \\
\hline Roraima & 95.774 hab. & 21,26 \\
\hline Brasil & 45.623 .910 hab. & 23,92 \\
\hline
\end{tabular}

Fonte: Elaborado pelos autores.

Como fica demonstrado, é a região Nordeste que possui um quantitativo maior, proporcionalmente, de pessoas com deficiência, destacando-se os Estados do Rio Grande do Norte, Paraíba e Ceará atingindo a casa acima de $27 \%$ da sua população.

Gráfico 01. Quantitativo proporcional de pessoas com deficiência nas grandes regiões - Brasil, $2010^{5}$

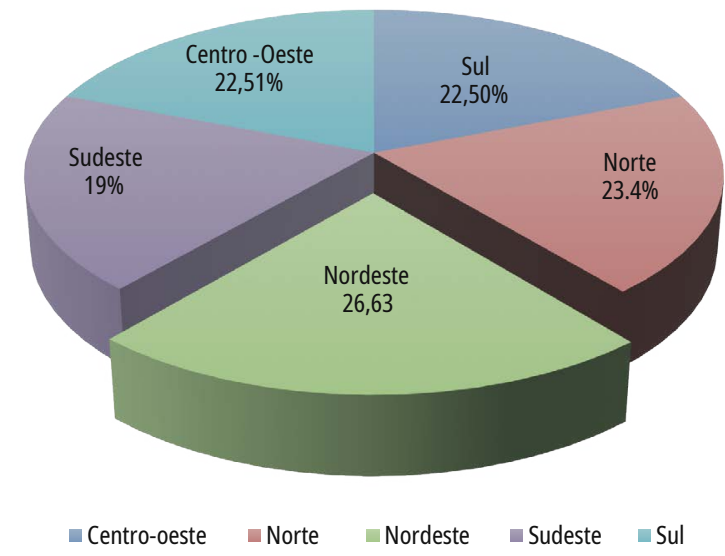

Fonte: Elaborado pelos autores.

É em face dessa realidade, fazendo uso de uma metodologia de análise qualitativa e utilizando-se métodos de abordagem hipotético-dedutivos de caráter descritivo e analítico, buscar-se-á fazer uma apreciação da construção normativa, no sistema jurídico brasileiro, sobre os direitos construídos para as pessoas com deficiência. 


\section{Da promoção dos direitos das pessoas com deficiência como matéria de status constitucional}

A matéria sobre tratados internacionais sofreu uma nova modelagem a partir da reforma promovida pela Emenda Constitucional no 45/04, a qual ficou conhecida como "reforma do poder judiciário", acrescentando o $\$ 3^{\circ}$, no art. $5^{\circ}$, com a seguinte prescrição:

Art. 5. (...)

$\$ 3^{\circ}$ Os tratados e convenções internacionais sobre direitos humanos que forem aprovados, em cada Casa do Congresso Nacional, em dois turnos, por três quintos dos votos dos respectivos membros, serão equivalentes às emendas constitucionais.

Além disso, em 2006, por meio do Recurso Extraordinário $\mathrm{n}^{\circ} 466.343 / \mathrm{sP}$, o Supremo Tribunal Federal (STF) completa esse processo de redesenhamento do direito dos tratados. Doravante, é fulcral definir a figura do tratado internacional.

O tratado internacional seria um acordo escrito entre os Estados ou organizações internacionais, sobre uma matéria de interesse comum, regido pelo direito internacional, o qual pode conter dois ou mais documentos, como anexos e protocolos, onde estes auxiliam na regulamentação do documento principal. ${ }^{6}$

Os tratados internacionais, assim são conceituados por Valério Mazzuoli (2007):

(...). Portanto, sob o aspecto que ora nos ocupa, entende-se por tratado todo acordo formal, concluído entre os sujeitos de Direito Internacional Público, regido pelo direito das gentes e visando à produção de efeitos de direito para as partes contratantes. (...) (p. 133)

6 Assim encontra-se definido no artigo $2^{\circ}$, 1 , a figura do tratado na Convenção de Viena sobre o direito dos tratados, firmado em 1969: “'tratado' significa um acordo internacional concluído por escrito entre Estados e regido pelo Direito Internacional, quer conste de um instrumento único, quer de dois ou mais instrumentos conexos, qualquer que seja sua denominação específica”. Disponível em:.https://www.passeidireto.com/cadastro/passo1
Era consolidada, na jurisprudência do STF, a teoria da equivalência legislativa entre os tratados internacionais e as leis ordinárias, ou seja, os tratados internacionais, ratificados pelo Congresso Nacional, adentravam no sistema jurídico brasileiro com status de lei ordinária. Essa teoria prevaleceu por mais de três décadas na jurisprudência do STF.

A partir de uma decisão, em sede de Recurso Extraordinário (RE no 466343/sP, rel. Min. Cezar Peluso, 22.11.2006), ${ }^{7}$ ao tratar da prisão civil do depositário infiel, previsto no art. $5^{\circ}$, LXVII e sua análise conforme a Convenção Americana de Direitos Humanos, reconheceu que tratados internacionais de direito humanos que não foram aprovados com o quórum de $3 / 5$, em dois turnos, em cada casa do congresso (procedimento respectivo das emendas constitucionais) deveriam portar o status normativos de supralegalidade. Ou seja, acima na lei ordinária e abaixo da norma constitucional.

De tal sorte, em matéria de tratados internacionais, têm-se as seguintes equivalências: tratados

7 "Em seguida, o Min. Gilmar Mendes acompanhou o voto do relator, acrescentando aos seus fundamentos que os tratados internacionais de direitos humanos subscritos pelo Brasil possuem status normativo supralegal, o que torna inaplicável a legislação infraconstitucional com eles conflitantes, seja ela anterior ou posterior ao ato de ratificação e que, desde a ratificação, pelo Brasil, sem qualquer reserva, do Pacto Internacional dos Direitos Civis e Políticos (art. 11) e da Convenção Americana sobre Direitos Humanos - Pacto de San José da Costa Rica (art. $\left.7^{\circ}, 7\right)$, não há mais base legal para a prisão civil do depositário infiel. Aduziu, ainda, que a prisão civil do devedor-fiduciante viola o princípio da proporcionalidade, porque o ordenamento jurídico prevê outros meios processuais-executórios postos à disposição do credor-fiduciário para a garantia do crédito, bem como em razão de o DL 911/69, na linha do que já considerado pelo relator, ter instituído uma ficção jurídica ao equiparar o devedor-fiduciante ao depositário, em ofensa ao princípio da reserva legal proporcional. Após os votos dos Ministros Cármen Lúcia, Ricardo Lewandowski, Joaquim Barbosa, Carlos Britto e Marco Aurélio, que também acompanhavam o voto do relator, pediu vista dos autos o Min. Celso de Mello”. (RE-466343) (Grifos nossos). Informativo $n^{\circ} 449$, de 20 a 24 de novembro de 2006 do STF. 
internacionais que não sejam de direitos humanos aderem ao patamar de lei ordinário; tratados internacionais de direitos humanos que obedecerem a regra do art. $5^{\circ}, \S 3$ da Constituição, teriam status de emendas à constituição; por fim, tratados internacionais de direitos humanos, não aprovados segundo os tramites de emenda constitucional, teriam o porte de dispositivos supralegais.

Gráfico 2. Tratados internacionais

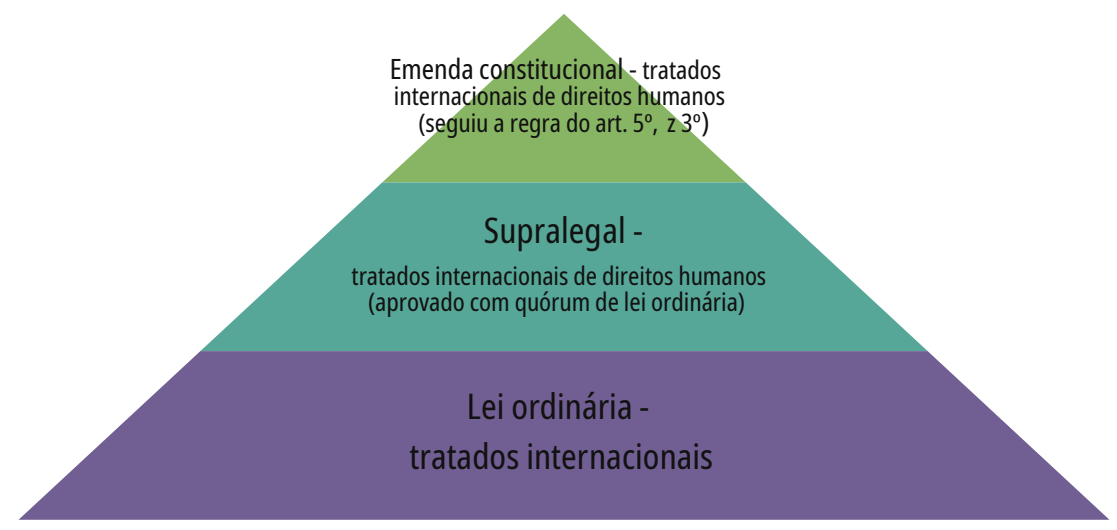

Fonte: Elaborado pelos autores.

Diga-se que até a presente data, o único tratado/ convenção internacional ratificado segundo a regra constitucional do art. $5^{\circ}, \$ 3^{\circ}$ da Constituição Federal foi a Convenção Internacional sobre os Direitos das Pessoas com Deficiência e seu protocolo facultativo, assinados em Nova York, em 30 de março de 2007, promulgado através do Decreto no 6.949/09.

De tal sorte, a normativa da Convenção Internacional sobre os Direitos das Pessoas com Deficiência tem status constitucional, agregando-se ao bloco de constitucionalidade, determinando o conjunto de regras e princípios basilares para a estruturação de um direito garantidor para as pessoas com deficiência no Brasil.

Lembrar o ensinamento da professora Piovesan, que ao interpretar o $\$ 2^{\circ}$ do art. $5^{\circ}$ da Constituição Federal, ${ }^{8}$ entende que os tratados internacionais de proteção aos direitos humanos, independentemente do quórum de aprovação ser

8 Art. $5^{\circ}$. $\S 2^{\circ}$ Os direitos e garantias expressos nesta Constituição não excluem outros decorrentes do regime e dos princípios por ela adotados, ou dos tratados internacionais em que a República Federativa do Brasil seja parte. de Emenda Constitucional, vêm por incorpora-se ao sistema jurídico brasileiro com status de norma constitucional em face, dentre outras coisas, do caráter materialmente constitucional dos direitos fundamentais, vindo tais tratados, especialmente aqueles anteriores a EC no $45 / 04$, a compor o bloco de constitucionalidade da ordem brasileira (2015, ps. $120-121){ }^{9}$

Segue a lapidar lição da professora Piovesan (2015):

Ao efetuar a incorporação, a Carta atribui aos direitos internacionais uma natureza especial e diferenciada, qual seja, a natureza de norma constitucional. Os direitos enunciados nos tratados de Direitos Humanos de que o Brasil é parte integram,

9 “A Constituição de 1988 recepciona os direitos enunciados em tratados internacionais de que o Brasil é parte, conferindo-lhe natureza de norma constitucional. Isto é, os direitos constantes nos tratados internacionais integram e complementam o catálogo de direitos constitucionalmente previstos, o que justifica estender a esses direitos o regime constitucional conferido aos demais direitos e garantias fundamentais”. (Piovesan, 2015, p. 124). 
portanto, o elenco dos direitos constitucionalmente consagrados. Essa conclusão advém ainda de interpretação sistemática e teológica do texto, especialmente em face da força expansiva dos valores da dignidade humana e dos direitos fundamentais, como parâmetros axiológicos a orientar a compreensão do fenômeno constitucional. (p. 118)

Nessa ótica interpretativa, a Convenção Internacional sobre os Direitos das Pessoas com Deficiência teria status de norma constitucional, independentemente da obediência do quórum qualificado, ${ }^{10}$ determinado no art. $5^{\circ}, \$ 3^{\circ}$ da Constituição, compondo o plexo de direitos fundamentais tendo em vista o caráter especial desses tratados que remete diversas obrigações entre o Estado e o cidadão, em atendimento ao princípio da prevalência da norma mais favorável, consolidando, assim, a visão da Constituição como uma ordem jurídica fundamental aberta.

Todavia, em decorrência do processo de constitucionalização da Convenção Internacional sobre os Direitos das Pessoas com Deficiência, não apenas no seu aspecto material, mas também, em seu aspecto formal, a presente convenção não estar suscetível ao processo de denúncia, ou seja, de retirada do Brasil da Convenção, compondo esses direitos e garantias das pessoas com deficiência conteúdo de cláusula pétrea, o qual constitui limite

10 "Reitere-se que, por força do art. $5^{\circ}, \S 2^{\circ}$, todos os tratados de direitos humanos, independentemente do quorum de sua aprovação, são materialmente constitucionais, compondo o bloco de constitucionalidade. O quórum qualificado está tão somente a reforçar tal natureza, ao adicionar um lastro formalmente constitucional aos tratados ratificados, propiciando a 'constitucionalização formal' dos tratados de direitos humanos no âmbito jurídico interno. Como já defendido por este trabalho, na hermenêutica emancipatória dos direitos há que imperar uma lógica material e não formal, orientada por valores, a celebrar o valor fundante da prevalência da dignidade humana. À hierarquia de valores deve corresponder uma hierarquia de normas”, e não o oposto. Vale dizer, “a preponderância material de um bem jurídico, como é o caso de um direito fundamental, deve condicionar a forma no plano jurídico-normativo, e não ser condicionado por ela”. (Piovesan, 2015, p. 138). material para alteração da constituição, conforme o art. 60, $\$ 4^{\circ}$, IV da Constituição de $1988 .{ }^{11} \mathrm{e}^{12}$

Em suma, com o processo de constitucionalização formal da Convenção, há uma renúncia ao direito de retirada do tradado ou convenção.

Além do mais, por tratar-se de direitos e garantias fundamentais da pessoa, a Convenção, supra, tem aplicação imediata, nos termos do art. $5^{\circ}, \$ 1^{\circ}$ da Constituição Federal, o que acarreta a desnecessidade de legislação infraconstitucional para lhe dar eficácia, já constituindo, desde já, direito subjetivo do cidadão passível de exigibilidade.

Nesse sentido Piovesan (2015):

A incorporação automática do Direito Internacional dos Direitos Humanos pelo direito brasileiro - sem que se faça necessário um ato jurídico complementar para sua exigibilidade e implementação

11 Constituição Federal. Art. 60. § $4^{\circ}$ Não será objeto de deliberação a proposta de emenda tendente a abolir:

I - A forma federativa de Estado;

II - O voto direto, secreto, universal e periódico; III - A separação dos Poderes;

IV - Os direitos e garantias individuais.

12 "Ainda que todos os tratados de direitos humanos sejam recepcionados em grau constitucional, por veicularem matéria e conteúdo essencialmente constitucional, importa realçar a diversidade de regimes jurídicos que se aplica aos tratados apenas materialmente constitucionais e aos tratados que, além de materialmente constitucionais, também são formalmente constitucionais. E a diversidade de regimes jurídicos atém-se à denúncia, que é o ato unilateral pelo qual um Estado se retira de um tratado. Enquanto os tratados materialmente constitucionais podem ser suscetíveis de denúncia, os tratados material e formalmente constitucionais, por sua vez, não podem ser denunciados.

Ao se admitir a natureza constitucional de todos os tratados de direitos humanos, há que ressaltar que os direitos constantes nos tratados internacionais, como os demais direitos e garantias individuais consagrados pela Constituição, constituem cláusula pétrea e não podem ser abolidos por meio de emenda à Constituição, nos termos do art. 60, § $4^{\circ}$. Atente-se que as cláusulas pétreas resguardam o núcleo material da Constituição, que compõe os valores fundamentais da ordem constitucional. (...)”. (Piovesan, 2015, p. 149). 
- traduz relevantes consequências no plano jurídico. De um lado, permite ao particular a invocação direta dos direitos e liberdades internacionalmente assegurados, e, por outro, proíbe condutas e atos violadores a esses mesmos direitos, sob pena de invalidação. Consequentemente, "a partir da entrada em vigor do tratado internacional, toda norma preexistente que seja com ele incompatível perde automaticamente a vigência”. Ademais, passa a ser recorrível qualquer decisão judicial que violar as prescrições do tratado - eis aqui uma das sanções aplicáveis na hipótese de inobservância dos tratados. (p. 156) ${ }^{13}$

\section{Do plexo de direitos das pessoas com deficiência}

\section{Da tutela jurídica da pessoa com deficiência na normatividade consumerista}

Em 1990, em cumprimento a determinação constitucional, previsto no art. 48 dos Atos de Disposição Constitucionais Transitórias, ${ }^{14}$ tem-se a publicação da Lei no 8.078, que institui o Código de Defesa do Consumidor, a qual vem por inovar sensivelmente no ordenamento jurídico brasileiro, e sendo reconhecida como uma das mais modernas legislações de proteção ao consumidor do mundo.

Em suma, com Código de Defesa do Consumidor criou-se um microssistema que vem por reconhecer a vulnerabilidade daquele envolvido numa relação de consumo, criando um plexo de normas protetivas com o intuito de igualar ou tentar

13 “Em outras palavras, não será mais possível a sustentação da tese segundo a qual, com a ratificação, os tratados obrigam diretamente aos Estados, mas não geram direitos subjetivos para os particulares, enquanto não advém a referida intermediação legislativa. Vale dizer, toma-se possível a invocação imediata de tratados e convenções de direitos humanos, dos quais o Brasil seja signatário, sem a necessidade de edição de ato com força de lei, voltado à outorga de vigência interna aos acordos internacionais”. (Piovesan, 2015, p. 156).

14 АDCT. Art. 48. O Congresso Nacional, dentro de cento e vinte dias da promulgação da Constituição, elaborará código de defesa do consumidor. diminuir a diferença abissal entre o fornecedor e o consumidor, no seio dessa sociedade de consumo de massa.

Sem dúvida que pode citar como medidas de grande relevo a proteção do consumidor, que se destaca por si só, o reconhecimento pelo código consumerista a presunção absoluta da vulnerabilidade do consumidor, ${ }^{15}$ a possibilidade da inversão do ônus da prova quando da verossimilhança ou da hipossuficiência do consumidor; ${ }^{16}$ e a aplicação, em regra geral, da responsabilidade objetiva em caso de fato e vício do consumo, ou seja, tem-se a desnecessidade de aferir o elemento subjetivo da conduta do fornecedor. ${ }^{17}$

Chama-se a atenção do caso de vicio do produto, por exemplo, onde há a quebra da expectativa

15 Código de Defesa do Consumidor. Art. $4^{\circ}$ A Política Nacional das Relações de Consumo tem por objetivo o atendimento das necessidades dos consumidores, o respeito à sua dignidade, saúde e segurança, a proteção de seus interesses econômicos, a melhoria da sua qualidade de vida, bem como a transparência e harmonia das relações de consumo, atendidos os seguintes princípios: I - reconhecimento da vulnerabilidade do consumidor no mercado de consumo; (...)

16 Código de Defesa do Consumidor. Art. $6^{\circ}$ São direitos básicos do consumidor: (...) viII - A facilitação da defesa de seus direitos, inclusive com a inversão do ônus da prova, a seu favor, no processo civil, quando, a critério do juiz, for verossímil a alegação ou quando for ele hipossuficiente, segundo as regras ordinárias de experiências;

17 Código de Defesa do Consumidor. Art. 12. O fabricante, o produtor, o construtor, nacional ou estrangeiro, e o importador respondem, independentemente da existência de culpa, pela reparação dos danos causados aos consumidores por defeitos decorrentes de projeto, fabricação, construção, montagem, fórmulas, manipulação, apresentação ou acondicionamento de seus produtos, bem como por informações insuficientes ou inadequadas sobre sua utilização e riscos. (Grifos nossos).

Art. 14. O fornecedor de serviços responde, independentemente da existência de culpa, pela reparação dos danos causados aos consumidores por defeitos relativos à prestação dos serviços, bem como por informações insuficientes ou inadequadas sobre sua fruição e riscos. (Grifos nossos) 
do consumidor em relação à quantidade ou qualidade do produto adquirido, onde o art. $18, \$ 1^{\circ}$ do Código de Defesa do Consumidor (CDC) determina a regra de até 30 dias para sanar o vício, podendo, após esse prazo, o consumidor, quando do vicio não sanado, exigir uma das três alternativas possíveis:

I - A substituição do produto por outro da mesma espécie, em perfeitas condições de uso;

II - A restituição imediata da quantia paga, monetariamente atualizada, sem prejuízo de eventuais perdas e danos;

III - O abatimento proporcional do preço.

Todavia, quando de produto essencial a pessoa com deficiência, como o caso de próteses, órteses, cadeiras de roda, etc., cujo vício desses produtos comprometeram a melhor superação das barreiras limitantes ao seu desenvolvimento, não se deve coadunar-se com o longínquo prazo de 30 dias, ou da dependência de perícia para substituição, mas sim, a aplicação imediata das alternativas o $\$ 1^{\circ}$ do art. 18 do CDC.

Esse é o melhor entendimento, pois como reconhecido no Recurso Especial n ${ }^{\circ}$ 931.513/RS, ${ }^{18}$ quando da figura do consumidor com deficiência ter-se-ia um consumidor hiper-vulnerável, ${ }^{19}$ devendo a normativa do Código de Defesa do Consumidor se amoldar às especificidades desse sujeito consumidor. Nesse sentido, afere-se:

Pela essencialidade desses serviços e produtos destinados à pessoa com deficiência, caso eles apresentem vícios de qualidade, não deve ser permitida a concessão do prazo de trinta (30) dias para que o

18 Superior Tribunal de Justiça (STJ). $1^{\circ}$ Seção, RESP $n^{\circ}$ 931.513/RS, rel. Min. Carlos Fernandes Mathias (Juiz Federal convocado do Tribunal Regional Federal (TRF) $1^{\circ}$ Região), Rel. para o acordão Min. Herman Benjamin, julgado em 25/11/09, publicado no Diário da Justiça Eletrônico (DJE) em 27/10/10.

19 "Dessa forma, analisando o deficiente consumidor à luz do Código de Defesa do Consumidor combinado com as normas constitucionais e a Convenção dos Direitos da Pessoa com Deficiência, verificamos que esse segmento tem um plus de vulnerabilidade em relação ao consumidor ordinário. (...)”. (Costa Filho, 2012, p. 402). fornecedor sane ou troque o produto ou realize novo serviço, muito menos prazos mais elásticos contidos em contratos abusivos. A substituição do produto ou a realização do serviço essencial têm que ser imediatas, senão obsta a autonomia e independência da pessoa com restrição física, sensorial ou mental, e considerando que os dispositivos referidos do CDC determinam a responsabilidade solidária de todos os fornecedores da cadeia produtiva ou do serviço contratado, cabe ao consumidor exigir de qualquer um deles a concretização do pactuado. (...) (Costa Filho, 2012, p. 405)

Segue trecho do voto do Ministro Herman Benjamin, no Resp no 931.513/RS:

(...) A categoria ético-política, e também jurídica, dos sujeitos vulneráveis inclui um subgrupo de sujeitos hiper-vulneráveis, entre os quais se destacam, por razões óbvias, as pessoas com deficiência física, sensorial ou mental.

(...) A tutela dos interesses e direitos dos hiper-vulneráveis é de inafastável e evidente conteúdo social, mesmo quando a Ação Civil Pública, no seu resultado imediato, aparenta tutelar apenas uma única pessoa. (...)

(...) Ao se proteger o hiper-vulnerável, a rigor quem verdadeiramente acaba beneficiada é a própria sociedade, porquanto espera o respeito ao pacto coletivo de inclusão social imperativa, que lhe é caro, não por sua faceta patrimonial, mas precisamente por abraçar a dimensão intangível e humanista dos princípios da dignidade da pessoa humana e da solidariedade. (...)

No trecho do Recurso Especial retro fica evidenciado o reconhecimento da figura do hiper-vulnerável para fins consumeristas.

\section{Dos direitos da pessoa com deficiência e do direito fundamental a assistência social}

Um dos braços da seguridade social é assistência social, ${ }^{20}$ tendo está uma intensa participação no

20 "O segmento assistencial da seguridade" tem como propósito nuclear preencher as lacunas deixadas pela previdência social, já que esta, (...), não é ex- 
que tange a promoção da dignidade das pessoas com deficiência, independentemente de qualquer contribuição, em clara obediência ao princípio da solidariedade, seja através da habilitação ou reabilitação, seja com o benefício de prestação continuada, ${ }^{21}$ na razão de um salário mínimo, nos termos do art. 203, IV e V da Constituição Federal:

Art. 203. A assistência social será prestada a quem dela necessitar, independentemente de contribuição à seguridade social, e tem por objetivos:

(...)

IV - a habilitação e reabilitação das pessoas portadoras de deficiência e a promoção de sua integração à vida comunitária;

V - a garantia de um salário mínimo de benefício mensal à pessoa portadora de deficiência e ao idoso que comprovem não possuir meios de prover à própria manutenção ou de tê-la provida por sua família, conforme dispuser a lei.

Todavia, esse benefício de prestação continuada da assistência social, no valor de um salário mínimo, possuía uma séria barreira para a sua concessão, nos termos do art. $20, \$ 3^{\circ}$ da lei que dispõe sobre a organização da assistência social

tensível a todo e qualquer indivíduo, mas somente aos que contribuem para o sistema, além de seus dependentes,

Muitas pessoas não exercem atividades remuneradas, daí serem desprovidas de qualquer condição de custear a proteção previdenciária. Ao Estado, portanto, urge manter segmento assistencial direcionado a elas. "Não compete à previdência social a manutenção de pessoas carentes; por isso, a assistência social é definida como atividade complementar ao seguro social”. (Ibrahim, 2015, p. 13).

21 “Não é benefício previdenciário devido à sua lógica de funcionamento: não carece de contribuição do beneficiário, bastando a comprovação da condição de necessitado. Veio substituir a renda mensal vitalícia, que era equivocadamente vinculada à previdência social, em razão de seu caráter evidentemente assistencial. Ainda hoje esta prestação é frequentemente denominada ainda de renda mensal vitalícia ou amparo assistencial”. (Ibrahim, 2015, p. 17).
(Lei $\left.\mathrm{n}^{\circ} 8.742 / 93\right),{ }^{22}$ pois é a partir do rendimento mensal da família que será aferido para constatar ou não a carência econômica, no que tange ao sustento da pessoa com deficiência.

No citado dispositivo legal imputa-se como família incapaz economicamente aquela com renda mensal per capita inferior a $1 / 4$ do salário-mínimo. Destarte, em referência a unidade familiar, o art. 20, $\$ 1^{\circ}$ da Lei no 8.742/93 (com redação alterada pela lei $\left.n^{\circ} 12.435 / 11\right)$, explicita como família as seguintes figuras: “(...), o cônjuge ou companheiro, os pais e, na ausência de um deles, a madrasta ou o padrasto, os irmãos solteiros, os filhos e enteados solteiros e os menores tutelados, desde que vivam sob o mesmo teto".

Afira bem que o singelo valor do salário mínimo, hoje, em vigência no Brasil, de $\mathrm{R} \$ 788,00$, é incapaz de prover as necessidades básicas de uma única pessoa, quanto mais de uma pessoa com deficiência, que, em maior ou menor grau, tem maiores necessidades.

De tal sorte, não se aferia lógica no art. $20, \$ 3^{\circ}$ da Lei $n^{\circ} 8.742 / 93$, que vinculava à concessão do parco benefício assistencial à esdrúxula regra da renda familiar mensal, per capita, abaixo de um $1 / 4$ do salário-mínimo, ou seja, abaixo de R $\$ 197$ reais.

Em suma, estar-se-ia a condicionar o benefício a pessoa com deficiência, a qual possui uma família que vive em profundo estado de miserabilidade, perto da linha da pobreza ou abaixo. ${ }^{23}$

Essa evidente desproporcionalidade, violador patente do sentimento de justiça, deu azo a diversos questionamentos em sede judicial, como ressalta Savaris (2012):

Quando é negado o benefício assistencial porque a família não foi considerada carente (não foi

22 Lei $n^{\circ}$ 8.742/93. Art. 20. § 3o Considera-se incapaz de prover a manutenção da pessoa com deficiência ou idosa a família cuja renda mensal per capita seja inferior a 1/4 (um quarto) do salário-mínimo. (Grifos nossos).

23 O Banco Mundial define o valor da linha da pobreza a partir da renda individual de US\$1,25 dólares ao dia. Convertendo, hoje, com o dólar em alta, isso equivaleria, em um mês, aproximadamente a $\mathrm{R} \$$ 150,00 reais. 
considerada incapaz de prover o sustento da pessoa com deficiência porque a renda mensal per capita familiar não é inferior a 1/4 do salário mínimo), a questão pode ser discutida judicialmente. E é interessante notar que a grande maioria das decisões judiciais tem expressado que o fato de a renda mensal ser superior ao limite disposto pela legislação não impede, por si só, a concessão do benefício, desde que no caso concreto fique comprovada a situação de carência econômica. (p. 239)

Entretanto, em sede constitucional, quando questionado através da ação direta de inconstitucionalidade $\mathrm{n}^{\circ} 1.22-1 / \mathrm{DF}$, nos idos de 1998, o pleno do Superior Tribunal Federal, considerou constitucional o requisito objetivo dado pelo art. $20, \$ 3^{\circ}$ da Lei $n^{\circ} 8.742 / 93$.

Contudo, apesar da decisão do Supremo Tribunal Federal (STF), a matéria não ficou pacífica no âmbito judicial.

Afira que chegou a existir uma súmula da Turma Nacional de Uniformização dos Juizados Especiais Federais (de número 11), ${ }^{24}$ publicado em 2004, que consolidava o entendimento de que havia possibilidade de concessão do benefício de prestação continua, mesmo em casos de renda familiar superior a $1 / 4$ do salário mínimo. Todavia, em face da intransigência do STF em manter seu entendimento sobre a constitucionalidade do art. $20, \$ 3^{\circ}$ da Lei $n^{\circ} 8.742 / 93$, a referida súmula acabou sendo cancelada em 2006.

Apesar disso, continuaram a aplicar o conteúdo veiculado da cancelada súmula $n^{\circ} 11$. Nessa esteira, decisão do STJ, de 2007, que entende a possibilidade da comprovação da miserabilidade por outros elementos, não se vinculando ao quantum de $1 / 4$ do salário-mínimo para a concessão do benefício de prestação continuada da assistência social:

Previdenciário. Benefício de prestação continuada. Assistência social. Previsão constitucional.

24 Turma Nacional de Uniformização dos Juizados Especiais Federais. Súmula ${ }^{\circ} 11$. A renda mensal, per capita, familiar, superior a $1 / 4$ (um quarto) do salário mínimo não impede a concessão do benefício assistencial previsto no art. $20, \S 3^{\circ}$ da Lei $n^{\circ}$. 8.742 de 1993, desde que comprovada, por outros meios, a miserabilidade do postulante.
Benefício recebido por parente do autor. Cômputo do valor para verificação de miserabilidade. Impossibilidade. Art. 34 da lei $n^{\circ}$ 10.741/2003. Interpretação restritiva ao bpc. Art. $20, \S 3^{\circ}$, da lei $n^{\circ}$ 8.742/93. Possibilidade de aferição da miserabilidade por outros meios. Precedentes. Recurso especial provido.(...)

3. A Terceira Seção deste Superior Tribunal consolidou o entendimento de que o critério de aferição da renda mensal previsto no $₫ 3^{\circ}$ do art. 20 da Lei ${ }^{\circ}$ 8.742/93 deve ser tido como um limite mínimo, um quantum considerado insatisfatório à subsistência da pessoa portadora de deficiência ou idosa, não impedindo, contudo, que o julgador faça uso de outros elementos probatórios, desde que aptos a comprovar a condição de miserabilidade da parte e de sua família. (Grifo nosso)

4. Recurso especial a que se dá provimento.

(Resp 841060/SP, Rela. Mina. Maria Thereza de Assis Moura, DJ 25/06/2007).

Em decorrência dessa patente controvérsia no que se refere à aplicação do critério da renda familiar per capita, a qual precisava de um desfecho, o STF, no Recurso Extraordinário no $567.985 / \mathrm{MT}$, em 2013, reviu o seu posicionamento, declarando a inconstitucionalidade do art. $20, \S 3^{\circ}$ da Lei $n^{\circ}$. 8.742 de 1993.

Nesses termos, segue trecho do voto do ministro Gilmar Mendes:

Como a lei permaneceu inalterada, elaboraram-se maneiras de se contornar o critério objetivo e único estipulado pela Lei Orgânica da Assistência Social (LOAS) e de se avaliar o real estado de miserabilidade social das famílias com entes idosos ou deficientes.

Paralelamente, foram editadas leis que estabeleceram critérios mais elásticos para a concessão de outros benefícios assistenciais, tais como: a Lei 10.836/2004, que criou o Bolsa Família; a Lei 10.689/2003, que instituiu o Programa Nacional de Acesso à Alimentação; a Lei 10.219/01, que criou o Bolsa Escola; a Lei 9.533/97, que autoriza o Poder Executivo a conceder apoio financeiro a Municípios que instituírem programas de garantia de renda mínima associados a ações socioeducativas. 
O Supremo Tribunal Federal, em decisões monocráticas, passou a rever anteriores posicionamentos acerca da intransponibilidade dos critérios objetivos.

Verificou-se a ocorrência do processo de inconstitucionalização decorrente de notórias mudanças fáticas (políticas, econômicas e sociais) e jurídicas (sucessivas modificações legislativas dos patamares econômicos utilizados como critérios de concessão de outros benefícios assistenciais por parte do Estado brasileiro). ${ }^{25}$

O ministro Marcus Aurélio, apesar de ter apenas negado provimento ao recurso, em seu voto trata da inconstitucionalidade do artigo legal, supra:

Mostra-se patente que o artigo $20, \S 3^{\circ}$, da Lei $n^{\circ} 8.742 / 93$, embora não seja, só por si, inconstitucional, gerou situação concreta de inconstitucionalidade. A incidência da regra traduz falha no dever, criado pela Carta, de plena e efetiva proteção dos direitos fundamentais, resultante da eficácia positiva de tais direitos, cuja concretização é condição essencial à construção de uma sociedade mais justa e, portanto, civilizada. (...)

Chama-se atenção ao Decreto no 6.214/07, que regulamenta o benefício de prestação continuada da assistência social devido à pessoa com deficiência e ao idoso, que após a edição do Decreto ${ }^{\circ}$ 6564/08 e do Decreto $n^{\circ}$ 7.617/11, ficou instituído o modelo de avaliação da deficiência, não apenas em seu aspecto médico (visão clássica da deficiência, associado a uma patologia), como agregou-se a sua avaliação social, onde a partir desse conjunto será determinado, não mais a "incapacidade", mas sim o grau de impedimento da pessoa com deficiência. ${ }^{26}$

25 RE 567.985/MT, Rel. Min. Marco Aurélio, redator do acordão Min. Gilmar Mendes, julgado em 18/04/2013.

26 Por meio da portaria interministerial AGU/MPS/MF/ SEDH/MP n ${ }^{\circ} 1$ de 27/01/2014 tem-se a criação do instrumento destinado à avaliação do segurado da Previdência Social e à identificação dos graus de deficiência, bem como define impedimento de longo prazo.
No art. $16, \$ 2^{\circ}$ do citado decreto regulamentador, com redação dada pelo Decreto no 7.617/11, explicitou o que caberia a cada tipo de avaliação:

Art. 16. (...)

$\$ 20$ A avaliação social considerará os fatores ambientais, sociais e pessoais, a avaliação médica considerará as deficiências nas funções e nas estruturas do corpo, e ambas considerarão a limitação do desempenho de atividades e a restrição da participação social, segundo suas especificidades.

Destaca-se que por meio da Lei $n^{\circ} 12.435 / 11$, que buscou atualizar a Lei da Assistência Social, a remuneração da pessoa com deficiência, na condição de aprendiz, não será contabilizada para fins de recebimento do benefício de prestação continuada, respeitando o limite de dois anos. ${ }^{27}$

Ou seja, a pessoa com deficiência pode receber concomitantemente tanto o benefício com a bolsa fruto da atividade contratada de aprendiz, pelo limite de dois anos. ${ }^{28}$

Importante frisar, que pelo Estatuto da Pessoa com Deficiência, o qual, ainda não entrou em vigor, ${ }^{29}$ é acrescido, além do rendimento fruto da

27 Lei $n^{\circ} 8.742 / 91$. Art. 20. § $9^{\circ}$ A remuneração da pessoa com deficiência na condição de aprendiz não será considerada para fins do cálculo a que se refere o § 30 deste artigo.

28 "Adicionalmente, a nova lei expressa que a remuneração da pessoa com deficiência na condição de aprendiz não será considerada para fins do cálculo da renda familiar. Era comum, em diversas situações, que um menor aprendiz, em razão de sua bolsa, excluísse o direito ao benefício assistencial de algum familiar, haja vista a elevação da renda per capita. Isso hoje não mais existe. Indo além, a lei prevê que a contratação de pessoa com deficiência como aprendiz não acarreta a suspensão do benefício de prestação continuada, limitado a 2 (dois) anos o recebimento concomitante da remuneração e do benefício. Ou seja, se a própria pessoa com deficiência for contratada como aprendiz, ainda assim permanecerá o benefício, mas limitado a dois anos”. (Ibrahim, 2015, p. 16).

29 O citado diploma legal tem uma vacatio legis de 180 dias. De tal sorte, vai entrar em vigor em meados de janeiro de 2016. 
aprendizagem, também decorrente do estágio supervisionado.

Por fim, a questão da habilitação e da reabilitação para as pessoas com deficiência foi lembrada no art. 26 da Convenção Internacional sobre os Direitos das Pessoas com Deficiência, ${ }^{30}$ pois sem dúvida muito mais importante do que um benefício de cunho monetário assistencialista, a promoção do desenvolvimento da autonomia, seja para fins de meras atividades do dia a dia, seja para fins de mercado de trabalho, proporcionado pela habilitação ou reabilitação é a verdadeira forma de atingir os auspícios do princípio da dignidade da pessoa humana.

30 Convenção Internacional sobre os Direitos das Pessoas com Deficiência.

Artigo. 26

1.Os Estados Partes tomarão medidas efetivas e apropriadas, inclusive mediante apoio dos pares, para possibilitar que as pessoas com deficiência conquistem e conservem o máximo de autonomia e plena capacidade física, mental, social e profissional, bem como plena inclusão e participação em todos os aspectos da vida. Para tanto, os Estados Partes organizarão, fortalecerão e ampliarão serviços e programas completos de habilitação e reabilitação, particularmente nas áreas de saúde, emprego, educação e serviços sociais, de modo que esses serviços e programas: (Grifos nossos)

a) Comecem no estágio mais precoce possível e sejam baseados em avaliação multidisciplinar das necessidades e pontos fortes de cada pessoa;

b) Apoiem a participação e a inclusão na comunidade e em todos os aspectos da vida social, sejam oferecidos voluntariamente e estejam disponíveis às pessoas com deficiência o mais próximo possível de suas comunidades, inclusive na zona rural. 2.Os Estados Partes promoverão o desenvolvimento da capacitação inicial e continuada de profissionais e de equipes que atuam nos serviços de habilitação e reabilitação.

3.Os Estados Partes promoverão a disponibilidade, o conhecimento e o uso de dispositivos e tecnologias assistivas, projetados para pessoas com deficiência e relacionados com a habilitação e a reabilitação. (Grifos nossos)

\section{Da proteção a pessoa com deficiência como bem jurídico penal}

Estar a se analisar o direito, de tal sorte, tem-se que estudar a figura do trabalhador dentro de um isolamento jurídico o qual é constituído por uma estrutura normativa de regras e princípios.

No que tange a legislação penal esparsa, tem-se a tipificação penal específica dada pela Lei no 7.853/89, assim prescreve os tipos penais que lesão o bem jurídico das pessoas com deficiência:Art. $8^{\circ}$ Constitui crime punível com reclusão de 1 (um) a 4 (quatro) anos, e multa:

I - recusar, suspender, procrastinar, cancelar ou fazer cessar, sem justa causa, a inscrição de aluno em estabelecimento de ensino de qualquer curso ou grau, público ou privado, por motivos derivados da deficiência que porta;

II - obstar, sem justa causa, o acesso de alguém a qualquer cargo público, por motivos derivados de sua deficiência;

III - negar, sem justa causa, a alguém, por motivos derivados de sua deficiência, emprego ou trabalho;

IV - recusar, retardar ou dificultar internação ou deixar de prestar assistência médico-hospitalar e ambulatorial, quando possível, à pessoa portadora de deficiência;

$\mathrm{V}$ - deixar de cumprir, retardar ou frustrar, sem justo motivo, a execução de ordem judicial expedida na ação civil a que alude esta Lei;

VI - recusar, retardar ou omitir dados técnicos indispensáveis à propositura da ação civil objeto desta Lei, quando requisitados pelo Ministério Público.

Todavia a apresente redação fora, recentemente, alterada pela Lei ${ }^{\circ} 13.146 / 15$, que institui o Estatuto da pessoa com deficiência, ficando o noval dispositivo, assim prescrito:

Art. 8o Constitui crime punível com reclusão de 2 (dois) a 5 (cinco) anos e multa:

I - recusar, cobrar valores adicionais, suspender, procrastinar, cancelar ou fazer cessar inscrição de aluno em estabelecimento de ensino de qualquer 
curso ou grau, público ou privado, em razão de sua deficiência;

II - obstar inscrição em concurso público ou acesso de alguém a qualquer cargo ou emprego público, em razão de sua deficiência;

III - negar ou obstar emprego, trabalho ou promoção à pessoa em razão de sua deficiência;

IV - recusar, retardar ou dificultar internação ou deixar de prestar assistência médico-hospitalar e ambulatorial à pessoa com deficiência;

$\mathrm{V}$ - deixar de cumprir, retardar ou frustrar execução de ordem judicial expedida na ação civil a que alude esta Lei;

VI - recusar, retardar ou omitir dados técnicos indispensáveis à propositura da ação civil pública objeto desta Lei, quando requisitados.

$\S 1$ lo Se o crime for praticado contra pessoa com deficiência menor de 18 (dezoito) anos, a pena é agravada em 1/3 (um terço).

$\$ 2$ o A pena pela adoção deliberada de critérios subjetivos para indeferimento de inscrição, de aprovação e de cumprimento de estágio probatório em concursos públicos não exclui a responsabilidade patrimonial pessoal do administrador público pelos danos causados.

$\$ 30$ Incorre nas mesmas penas quem impede ou dificulta o ingresso de pessoa com deficiência em planos privados de assistência à saúde, inclusive com cobrança de valores diferenciados.

$\$ 4$ o Se o crime for praticado em atendimento de urgência e emergência, a pena é agravada em $1 / 3$ (um terço).

A primeira alteração evidente é a agravação da pena mínima e máxima, que passa de 1 a 4 anos para 2 a 5 anos. Tal alteração tem severas repercussões. Pela prescrição inicial dada, a pena seria sempre cumprida em regime aberto (regime adotado para crimes que não sejam hediondos com pena não superior a 4 anos), ${ }^{31}$ além de dar ampla margem para o uso das penas alternativas (pena

31 Código Penal. Art. 33, $\S 2^{\circ}$, (...) c) o condenado não reincidente, cuja pena seja igual ou inferior a 4 (quatro) anos, poderá, desde o início, cumpri-la em regime aberto. privativa de liberdade não superior a 4 anos; crime sem violência ou grave ameaça; qualquer pena em caso de delito culposo; réu não reincidente em crime doloso; requisitos do art. 59 do Código Penal são indicativos de que a medida é suficiente). ${ }^{32}$

Além disso, como a pena mínima estava na casa de 1 ano, isso permitia o uso do instituto despenalizante da suspensão condicional do processo, criado e normatizado pela lei dos juizados especiais criminais (Lei no 9.099/95). ${ }^{33}$

Com a alteração trazida pelo Estatuto da pessoa com deficiência, vindo o mesmo aumentar as penas mínimas e máximas, a possibilidade do uso da suspensão condicional do processo fica descartado, bem como abre-se uma maior possibilidade do cumprimento da pena em um regime diverso do aberto, como o semiaberto (em crimes não hediondos e com pena acima de 4 anos até 8 anos). ${ }^{34}$

Atentar que o Estatuto da pessoa com deficiência está sobre uma vacatio legis de 180 dias e como a mesma vem por inovar com uma norma penal mais gravosa, a mesma só terá aplicabilidade em relação as condutas fáticas cometidas após decorrido esses 180 dias, em respeito ao princípio da irretroatividade da norma penal mais gravosa. 35

No que tange as alterações na redação do tipo penal, percebe-se que as mesmas não foram tão significativas, sendo poucos os acréscimos, havendo mais um aprimoramento na técnica legislativa redacional.

32 Art. 44 do Código Penal.

33 Lei $^{\circ}$ 9.099/95. Art. 89. Nos crimes em que a pena mínima cominada for igual ou inferior a um ano, abrangidas ou não por esta Lei, o Ministério Público, ao oferecer a denúncia, poderá propor a suspensão do processo, por dois a quatro anos, desde que o acusado não esteja sendo processado ou não tenha sido condenado por outro crime, presentes os demais requisitos que autorizariam a suspensão condicional da pena (art. 77 do Código Penal).

34 Código Penal. Art. 33, $\S 2^{\circ},(.$.$) b) o condenado não$ reincidente, cuja pena seja superior a 4 (quatro) anos e não exceda a 8 (oito), poderá, desde o princípio, cumpri-la em regime semiaberto;

35 Constituição Federal de 1988. Art. 5. (...). XL: a lei penal não retroagirá, salvo para beneficiar o réu; 
Por exemplo, as expressões "sem justa causa" e "quando possível". Afira a desnecessidades de tais expressões, pois as mesmas encontram-se implícitas no bojo do arcabouço do sistema jurídico penal. Perceba que se há uma conduta perpetrada de forma justificada, ter-se-á uma causa excludente da antijuridicidade, o que exclui a configuração da conduta típica, tornando repetitivo nua inserção no tipo penal. Já no inciso IV do art. $8^{\circ}$ que prescreve um tipo penal omissivo, o mesmo só existirá quando a omissão esteja na esfera da possibilidade, sendo redundante especificar "quando possível".

Além da ampliação de alguns núcleos do tipo, no inciso VI do art. $8^{\circ}$, estendeu-se a obrigatoriedade do fornecimento de dados técnicos, sob pena e configuração do tipo penal, não só a figura do Ministério Público, mas sim para todos legitimados a propositura da ação civil pública, destacando-se a figura da Defensoria Pública, hoje, com relevante atuação na defesa dos direitos das pessoas com deficiência.

Segue-se um quadro comparativo com as alterações perpetrado pelo Estatuto da pessoa com deficiência nos tipos penais prescrito no art. $8^{\circ} \mathrm{da}$ Lei $n^{\circ} 7.853 / 89$ :

Tabela 2. Antes e Depois do Estatuto da pessoa com deficiência

\section{Antes do Estatuto da pessoa Depois do Estatuto da}

com deficiência $\quad$ pessoa com deficiência

I - Recusar, suspender, procrastinar, cancelar ou fazer cessar, sem justa causa, a inscrição de aluno em estabelecimento de ensino de qualquer curso ou grau, público ou privado, por motivos derivados da deficiência que porta;

II - Obstar, sem justa causa, o acesso de alguém a qualquer cargo público, por motivos derivados de sua deficiência;

III - Negar, sem justa causa, a alguém, por motivos derivados de sua deficiência, emprego ou trabalho;
I - Recusar, cobrar valores adicionais, suspender, procrastinar, cancelar ou fazer cessar inscrição de aluno em estabelecimento de ensino de qualquer curso ou grau, público ou privado, em razão de sua deficiência;

II - Obstar inscrição em concurso público ou acesso de alguém a qualquer cargo ou emprego público, em razão de sua deficiência;

III - Negar ou obstar emprego, trabalho ou promoção à pessoa em razão de sua deficiência;
IV - Recusar, retardar ou dificultar internação ou deixar de prestar assistência médicohospitalar e ambulatorial, quando possível, à pessoa portadora de deficiência;

V - Deixar de cumprir, retardar ou frustrar, sem justo motivo, a execução de ordem judicial expedida na ação civil a que alude esta Lei;

VI - Recusar, retardar ou omitir dados técnicos indispensáveis à propositura da ação civil objeto desta Lei, quando requisitados pelo Ministério Público.

Fonte: Elaborado pelos autores.

Ainda, destaca-se a inovação do legislador, no $\$ 3^{\circ}$ do art. $8^{\circ}$, ao imputar as penas do caput aquele de impedir ou dificultar o ingresso de pessoas com deficiência nos planos de saúde, vindo a cobrar valores diferenciados.

Além disse criou duas majorante de $1 / 3$ da pena (aplicado na terceira fase da dosimetria da pena), quando dos núcleos do tipo foram perpetrados no atendimento de urgência e emergência (art. $\left.8^{\circ}, \$ 4^{\circ}\right)$ e quando realizado contra pessoa com deficiência menor de 18 anos (art. $8^{\circ}, \$ 1^{\circ}$ ).

Não se pode deixar que criticasse que o legislador na redação dos dois parágrafos que prescrevem a majorante de $1 / 3$ de pena foi atécnico, pois assim redigiu: “(...) a pena é agravada (...)”.

Em síntese: o legislador utilizou a palavra agravante quando da matéria tratada era uma majorante de pena. Na agravante o quanto da elevação da pena fica a critério do juiz, no uso da proporcionalidade, não sendo dado parâmetros pelo legislador, sendo aplicado na segunda fase da dosimetria da pena. Já as majorantes, o legislador especifica um quanto, por meio de um valor fracionado e o mesmo é aplicado na terceira fase da dosimetria da pena.

De tal sorte, ver-se que o legislador corrigiu certas atécnicas e criou outras. $\mathrm{O}$ bem da verdade nenhuma delas vem por comprometer o tê-los da lei e a sua aplicação.

O Estatuto da pessoa com deficiência, em seu corpo, criou quatro tipos penais novos, onde sobre 
eleva o tipo penal de reter ou utilizar cartão magnético ou assemelhado destinado ao recebimento de benefícios da pessoa com deficiente para obter vantagem indevida. Esse tipo penal fora apena com pena de 6 meses a 2 anos. Esse é o único tipo penal específico cuja conduta afeta bem jurídico de pessoa com deficiência que permite a transação penal, instinto despenalizante da lei dos juizados especiais, tendo em vista a pena máxima de 2 anos.

Segue um quadro com os novos tipos penais

Tabela 3. Novos tipos penais

\section{Crimes no Estatuto da pessoa com deficiência}

Art. 88. Praticar, induzir ou incitar discriminação de pessoa em razão de sua deficiência:

Pena - reclusão, de 1 (um) a 3 (três) anos, e multa.

(...)

Art. 89. Apropriar-se de ou desviar bens, proventos, pensão, benefícios, remuneração ou qualquer outro rendimento de pessoa com deficiência:

Pena - reclusão, de 1 (um) a 4 (quatro) anos, e multa. (...)

Art. 90. Abandonar pessoa com deficiência em hospitais, casas de saúde, entidades de abrigamento ou congêneres: Pena - reclusão, de 6 (seis) meses a 3 (três) anos, e multa. (...)

Art. 91. Reter ou utilizar cartão magnético, qualquer meio eletrônico ou documento de pessoa com deficiência destinados ao recebimento de benefícios, proventos, pensões ou remuneração ou à realização de operações financeiras, com o fim de obter vantagem indevida para si ou para outrem: Pena - detenção, de 6 (seis) meses a 2 (dois) anos, e multa. (...)

Fonte: Elaborado pelos autores.

Por fim, constata-se que no Código Penal não foi destinado um capítulo específico penalizando condutas contra pessoas com deficiência. Todavia, há diversas prescrições, no qual o crime perpetrado contra a pessoas com deficiência gera causa de aumento de pena ${ }^{36}$ e alguns poucos tipos pe-

36 Código Penal. Art. 121. (...) §7º, II - contra pessoa menor de 14 (catorze) anos, maior de 60 (sessenta) anos ou com deficiência. Art. 129. (...). § 11. Na hipótese do § 90 deste artigo, a pena será aumentada de um terço se o crime for cometido contra pessoa portadora de deficiência. nais que fazem referência à figura da pessoa com deficiência. ${ }^{37}$

\section{Da norma tributária como promotora das garantias da pessoa com deficiência}

O conjunto de normas tributárias dependendo da forma que for manipulado é um eficaz instrumento para a promoção do desenvolvimento, seja econômico como social. Uma forma de uso da norma tributária como promotor da inclusão social, da acessibilidade e da autonomia da pessoa com deficiência seria por meio do uso dos incentivos fiscais.

Os incentivos fiscais são um instrumento de extrafiscalidade imanente, constituidora de uma normatividade indutora, por incentivar ou desestimular certas condutas do cidadão, o qual pode ser utilizado afetando tanto a receita pública, por meio de isenções, diferimentos, remissão e anistia, quanto a despesa pública, por meio de subvenções, créditos presumidos e subsídios.

O professor Elali (2007) apresenta uma definição de incentivos fiscais a partir da premissa de que o mesmo é uma forma de manifestação da norma indutora tributária para regulação econômica: "Assim, os incentivos fiscais são os instrumentos hábeis para servirem à indução econômica nas hipóteses de benefícios que passam a ser outorgados para incentivar comportamentos específicos" (p. 114).

No que tange a norma tributária indutora, assim lapida o professor Schoueri (2005):

(...) quando se considera que por meio das normas tributárias indutoras, o legislador vincula a determinado comportamento um consequente, que poderá consistir em vantagem (estimulo) ou agravamento de natureza tributária, por meio de um corte, quando se extraem determinações individualizadas (...). (p. 40)

37 Código Penal. Art. 218-B. Submeter, induzir ou atrair à prostituição ou outra forma de exploração sexual alguém menor de 18 (dezoito) anos ou que, por enfermidade ou deficiência mental, não tem o necessário discernimento para a prática do ato, facilitá-la, impedir ou dificultar que a abandone: Pena - reclusão, de 4 (quatro) a 10 (dez) anos. 
Nesse leque de possibilidades para a constituição dos incentivos fiscais é palmar que o seu uso só se legitima quando calcados nos valores máximos constituidores do plexo normativo constitucional, seja na sua veiculação por meio de lei (princípio da legalidade), bem como um instrumento de promoção do universo de normas constitucionais programáticas, no que tange, por exemplo, aos incentivos à cultura, à tecnologia, ao desenvolvimento, à saúde, tendo por norteador de sua aplicabilidade o princípio da isonomia, com o fito de evitar os benefícios odiosos, para favorecimento de poucos em detrimento do universo dos cidadãos brasileiros.

É nesse contexto que há um aramado de normas tributárias indutoras, manifestada, geralmente, na modalidade de isenção tributária, afeto às pessoas com deficiência de forma a promover seu desenvolvimento e consequentemente, efetivando o conteúdo axiológico do princípio da dignidade da pessoa humana.

Abordar-se-á alguns exemplos de leis isentivas de impostos que afetam às pessoas com deficiência.

Nesse interim, através da Lei no $10.754 / 03$ que alterou a Lei no 8.989/95 tem-se a isenção do Imposto sobre Produtos Industrializados (IPI), referente ao automóvel com motor até 2.0, para as pessoas com deficiência, o que permite que as mesmas adquiram veículos automáticos e modificados para atender suas necessidades, garantindo assim, diretamente o seu direito ao transporte, viso que a precariedade do transporte público, e indiretamente, permite que a pessoa com deficiente integre-se a sociedade, permitindo que o mesmo tenha com deslocar-se para fins de educação, trabalho, lazer, etc.:

Art. $1^{\circ}$ Ficam isentos do Imposto Sobre Produtos Industrializados - IPI os automóveis de passageiros de fabricação nacional, equipados com motor de cilindrada não superior a dois mil centímetros cúbicos, de no mínimo quatro portas inclusive a de acesso ao bagageiro, movidos a combustíveis de origem renovável ou sistema reversível de combustão, quando adquiridos por:

(...)

IV - pessoas portadoras de deficiência física, visual, mental severa ou profunda, ou autistas, diretamente ou por intermédio de seu representante legal;
Com o mesmo fito de baratear o acesso ao veículo automotivo, tem-se a isenção do Imposto sobre Operações Financeiras (IOF), por meio da Lei $n^{\circ} 8.383 / 91$, quando de operações de financiamento de veículos automotivos:

Art. 72. Ficam isentas do IOF as operações de financiamento para a aquisição de automóveis de passageiros de fabricação nacional de até $127 \mathrm{HP}$ de potência bruta (SAE), quando adquiridos por:

$\mathrm{V}$ - pessoas portadoras de deficiência física, atestada pelo Departamento de Trânsito do Estado onde residirem em caráter permanente, cujo laudo de perícia médica especifique;

a) O tipo de defeito físico e a total incapacidade do requerente para dirigir automóveis convencionais;

b) A habilitação do requerente para dirigir veículo com adaptações especiais, descritas no referido laudo;

Ainda no âmbito da competência tributária federal, foi concedido isenção do imposto a pessoas com a deficiência de âmbito mental, através da Lei no $8.687 / 97$ :

Art. $1^{\circ}$ Não se incluem entre os rendimentos tributáveis pelo Imposto sobre a Renda e proventos de qualquer natureza as importâncias percebidas por deficientes mentais a título de pensão, pecúlio, montepio e auxílio, quando decorrentes de prestações do regime de previdência social ou de entidades de previdência privada.

Parágrafo único. Para fins do disposto nesta Lei, considera-se deficiente mental a pessoa que, independentemente da idade, apresenta funcionamento intelectual subnormal com origem durante o período de desenvolvimento e associado à deterioração do comportamento adaptativo.

Por fim, nesse último exemplo, por meio do Convênio ICMS $\mathrm{n}^{\circ} 27$, de 22 de abril de 2015, ${ }^{38}$ constituído no Conselho Nacional de Política Fazendária (CONFAZ), houve a prorrogação, até 31 de dezembro de 2015, de diversos convênios no que tange a isenção do imposto sobre circulação de mercadorias e prestação de serviços (ICMS), afetos

38 Publicado no Dou de 27.04.15. 
as pessoas com deficiência, seja na aquisição de equipamentos a entidades que atendam as pessoas com deficiência, seja para a saída de veículos a pessoas portadoras de deficiência física, visual, mental ou autista, seja para a importação de remédio e para aquisição de veículos para a Associação de Pais e Amigos dos Excepcionais (APAE):

Convênio ICMS 38/91, de 7 de agosto de 1991, que dispõe sobre a concessão de isenção do ICMS nas aquisições de equipamentos e acessórios destinados às instituições que atendam aos portadores de deficiência física, auditiva, mental, visual e múltipla;

Convênio ICMS 41/91, de 7 de agosto de 1991, que autoriza os Estados e o Distrito Federal a conceder isenção do ICMS na importação, pela APAE, dos remédios que especifica;

Convênio ICMS 91/98, de 18 de setembro de 1998, que autoriza os Estados de Santa Catarina, do Distrito Federal, do Espírito Santo e do Pará a conceder isenção do ICMS nas operações internas com veículos automotores adquiridos por Associação de Pais e Amigos dos Excepcionais (APAE);

Convênio ICMS 38/12, de 30 de março de 2012, que concede isenção do ICMS nas saídas de veículos destinados a pessoas portadoras de deficiência física, visual, mental ou autista;

Em todos os exemplos dados, afere-se a redução sensível da alta da carga tributária para bens destinados as pessoas com deficiência, de forma que as mesmas possam sair do ostracismo e integrar-se à sociedade, como pelo uso do automóvel, bem como pelo aumento da qualidade de vida e da saúde pelo acesso a remédios, cujas fabricantes, de regra, são empresas farmacêuticas estrangeiras, além de ter acesso a equipamentos e acessórios que permitem a superação de diversas barreiras ofertando autonomia a pessoa com deficiência, como próteses, aparelhos auditivos, etc.

\section{Do direito à saúde}

A Constituição Federal, em 1988, foi instituída com o intuito de garantir os direitos básicos e essenciais para os cidadãos brasileiros, neste interim pode-se citar o seu art. 23, II, onde é determina-se a competência comum dos entes da República
Federativa do Brasil, "cuidar, proteger e garantir a saúde bem como assistência pública das pessoas portadoras de deficiência”.

No Conjunto dos princípios que regem o Sistema Único de Saúde (SUS), referindo-se à Lei Orgânica da Saúde (Lei $n^{\circ}$ 8.080/90), que dispõe sobre as condições para a promoção, proteção e recuperação da saúde, a organização e o funcionamento dos serviços correspondentes e dá outras providências, destaca-se em seu art. $7^{\circ}$, I, II, III e IV, a garantia de acesso universal, integralidade da assistência sem preconceitos ou privilégios bem como a "preservação da autonomia das pessoas na defesa de sua integridade física e moral" em todos os níveis de complexidade.

Com o objetivo a promoção, proteção e recuperação da saúde da pessoa portadora de deficiência bem como da prevenção de agravos, com o intuito de desenvolver e articular ações intersetoriais com a participação popular foi aprovada a Política Nacional de Saúde da Pessoa Portadora de Deficiência, através da Portaria no 1.060 , de 05 de junho de 2002, do Ministério da Saúde.

Determina-se nesta que os órgãos e entidades vinculadas ao Ministério da Saúde promovam ações, programas, atividades e projetos relacionados com as temáticas desta política, e por muito tempo se considerou a pessoa portadora de deficiência, aquela que apresentava em caráter permanente, anormalidades ou perdas de sua estrutura anatômica, fisiológica ou psicológica que geriam incapacidade de desempenho de atividades dentro de padrões considerados normais para o ser humano, de acordo com o Decreto no 3.298/99.

A Organização Mundial de Saúde reapresentou, em 2001, uma nova conceituação na Classificação Internacional das Deficiências, Atividades e Participação, documento que refere aos princípios de apoio e potencialidades, não supervalorizando as limitações e incapacidades, considerando, portanto, a deficiência como uma anormalidade ou perda de uma estrutura ou função corporal, incluindo as mentais. Cujas atividades e suas limitações devem interagir diretamente com a pessoa portadora de deficiência e os fatores socioambientais.

Percebe-se que esta nova abordagem menos incapacitante propõe uma nova maneira, um novo olhar sobre os portadores de deficiência. 
Destarte, vislumbra-se que a atenção integral à saúde é uma diretriz que assegura a compreensão do ser humano em sua totalidade, percebe-se este como um dos eixos prioritários de uma política de saúde, onde o Sistema Único de Saúde e sua rede de atenção devem estar preparados para ofertar ações em todos os níveis de complexidade bem como os cuidados voltados as pessoas com deficiência, assegurando uma assistência de qualidade ofertada por equipe multiprofissional e garantindo assim os direitos perante o conceito ampliado de saúde e não mera ausência de doença.

\section{Conclusões}

Quando do uso da expressão "dignidade da pessoa humana", sabe-se da sua evidente redundância, pois toda pessoa é necessariamente humana. Todavia, é uma expressão corrente na doutrina, na jurisprudência e nas melhores redações legislativas, seja nacional ou internacional. Faz-se uso continuo desse pleonasmo para chamar a atenção de que se estar a falar de pessoas e não de objetos. Quando da coisificação da pessoa teve-se e tem-se os momentos mais trágicos da história da sociedade organizada.

Ao tratar de pessoa com deficiência, não está a tratar de um "problema”, de um "incapaz", mas sim, de uma pessoa diferente, como, em sua essência, todas as pessoas assim o são. A deficiência não está na pessoa, mas sim nas barreiras e muros sociais alavancados que impedem a promoção do pleno desenvolvimento dessas pessoas em sua diferença.

O devastador não é a sequela que uma pessoa tem, mas sim a marginalização que o olhar estigmatizante dado por uma sociedade em busca de um padrão valorado com status de perfeição.

Constata-se um verdadeiro microssistema jurídico em favor das pessoas com deficiência, cujos direitos foram elencados ao patamar de normativa constitucional, seja pelas disposições da própria Constituição Federal de 1988, seja pelas tratativas internacionais de direitos humanos, ratificados pelo Brasil.

Esse plexo de direitos, não é um favor ou um beneplácito, mas vem por tentar igualar o "peso da balança", quanto da vulnerabilidade das pessoas com deficiência, em face do longo processo histórico de segregação e ostracismo social, em evidente conotação de ações afirmativas, no melhor sentido do princípio da igualdade, em seus termos material/substancial.

Quando a sociedade "perfeita" deixar de olhar o próximo como uma pessoa com "defeito", "quebrada", "incapaz”, passando a aceitar a diferença ínsita dos membros que a compõe, não mais se terá um direito das pessoas com deficiência ou se falará pessoas com deficiência. Ter-se-á, apenas, pessoas.

\section{Referências Bibliográficas}

Augustin, I. (2012). Modelos de deficiência e suas implicações na educação inclusiva. IX Seminário de Pesquisa em Educação da Região Sul., Disponível em http:// www.espanholacessivel.ufc.br/modelo.pdf

Carvalho, R. C., \& Naujorks, M. I. (2006). Representações sociais: dos modelos de deficiência a leitura de paradigmas educacionais. Revista de Educação Especial, 27., Disponível em http://cascavel.ufsm.br/revistas/ojs2.2.2/index.php/educacaoespecial/article/view/4345

Costa Filho, W. M. (2012). A pessoa com deficiência no contexto das relações de consumo: tutela jurídica decorrente do Código de Defesa do Consumidor. Em Valença,C., Leite, G. S. Leite, G.S. \&. Leite, G.S. Manual dos direitos da pessoa com deficiência. São Paulo: Saraiva.

Elali, A. (2007). Tributação e regulação econômica - um exame da tributação como instrumento de regulação econômica na busca da redução das desigualdades regionais. São Paulo, Brasil: MP editora.

Ibrahim, F. Z. (2015). Curso de Direito Previdenciário (20 ed.). Niterói, Brasil: Impetus.

Mazzuoli, V. (2007). Curso de Direito Internacional Público. São Paulo, Brasil: RT. Disponível em https://www. academia.edu/36864062/Mazzuoli_curso_de_direito_internacional_publico

Piovesan, F. (2015). Direitos humanos e o Direito Constitucional Internacional (15ºd.). São Paulo, Brasil: Saraiva.

Savaris, J. A. (2012). Os direitos de previdência e assistência social da pessoa com deficiência. Em Valença. C., Leite, G. S., Leite, G. S \& LeiteG. S. Manual dos direitos da pessoa com deficiência. São Paulo, Brasil: Saraiva.

Schoueri, L. E. (2005). Normas tributárias indutoras e intervenção econômica. Rio de Janeiro, Brasil: Forense.

Werneck, C. (2005). Manual sobre desenvolvimento inclusivo. Rio de Janeiro, Brasil: wVA Editora. 
